\title{
Realigning the incentive system for China's primary healthcare providers
}

\section{Although reforms have reduced incentives to overprescribe, more needs to be done to link performance to quality and ensure primary care doctors are adequately paid, say Xiaochen $\mathbf{M a}$ and colleagues}

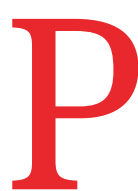

rimary healthcare is the foundation of an effective health system. ${ }^{1}$ A strong health workforce is widely recognised as a prerequisite for healthcare and an important determinant of health system performance. ${ }^{2}$ The performance of health professionals is determined by their competencies (for example, their medical knowledge and skills) and the incentives they are provided. ${ }^{3}$

China moved to a market economy in the 1980s. The role of government has been substantially reduced in all economic and social sectors, including healthcare. ${ }^{45}$ As a result, government subsidies that were available to primary care providers in the earlier centralised economy have been greatly reduced, and these providers have had to act as for-profit entities. At the facility level, in order for primary healthcare facilities to survive financially, they were allowed a $15 \%$ profit margin on drugs by the government. At the individual level, the income of primary healthcare doctors was linked to the revenue generated by the facilities they worked for. ${ }^{3}$ This incentive system resulted in primary healthcare doctors overprescribing drugs and high costs for diagnostic tests such as

\section{KEY MESSAGES}

- China changed the incentive system of primary healthcare providers as part of its 2009 healthcare reforms

- Drug mark-ups were replaced with government subsidies and a performance based salary system was introduced

- Incentives are still weak or misaligned and the use of primary healthcare facilities has decreased since 2010

- Further reforms should include a performance based salary system with an evaluation system linked to quality, adequate total pay, and career development opportunities for primary care professionals magnetic resonance imaging and computed tomography. ${ }^{3}$ This situation led to growing concerns about the quality of care, rising cost of healthcare, and a public distrust of the health system, particularly primary healthcare facilities. ${ }^{4-6}$

In order to deal with these public concerns, China started to reform its primary healthcare system as one of five key areas in its health system reforms which began in 2009. ${ }^{7}$ The reform focused on separating the operating revenue of primary healthcare facilities from their drug sales and realigning the incentives of primary healthcare providers with the public objective of improving the quality and efficiency of services. In this analysis, we summarise the policies that have been introduced over the past decade to provide incentives for primary healthcare professionals, discuss the achievements and gaps of the reform, and recommend possible actions to further progress.

\section{Realigning incentives in primary healthcare}

Box 1 summarises the main policies on incentives for primary healthcare providers. A set of policies was introduced to stop drug mark-ups as a source of financing for primary healthcare facilities. ${ }^{7}$ The mark-up used to be $15 \%$ of the drug sales. To compensate for the loss of revenue, the government established a comprehensive reimbursement scheme that provides financial subsidies to fully cover the deficit. ${ }^{9}$

A performance based salary system, fully funded by the government, was introduced to realign the incentives of primary healthcare professionals. ${ }^{8}$ The performance based salary is split into a basic salary (60$70 \%$ of the total salary) and a performance based bonus (30-40\%). Later policies indicated that the future salary reform

Box 1| Main policies on reforming incentives for primary healthcare providers

2009: Opinions on deepening health system reform ${ }^{7}$

- Aim: introduce a zero drug mark-up policy in all primary healthcare facilities

2009: Implementation of a performance based salary at primary healthcare facilities and public health institutions ${ }^{8}$

- Aim: establish a performance based salary system for primary care health professionals

2010: Establishment and optimisation of reimbursement scheme for primary healthcare facilities ${ }^{9}$ - Aim: implement a comprehensive reimbursement scheme in primary healthcare facilities 2011: Establishment of a general practitioner system ${ }^{10}$

- Aim: establish a general practitioner system and expand their career development path 2012: Guidelines on deepening health system reform during the 12 th five year plan period ${ }^{11}$ - Aim: increase the performance based bonus proportion of the total salary appropriately to increase the variation in total income distribution among primary healthcare employees

2013: Opinions on optimisation of the essential medicines policy and operating mechanism for primary health care facilities ${ }^{12}$

- Aim: permit primary healthcare facilities to allocate their operating profits to employee benefit fund and bonus fund

2016: Plan on deepening health system reform during the 13 th five year plan period ${ }^{13}$

- Aim: permit healthcare organisations to set their wage level above the ceiling of public funded organisation, and to use their operating profits for employee bonuses

2018: Opinions on optimising the training and incentive mechanism for general practitioner ${ }^{14}$

- Aim: set the total performance salary for primary healthcare facilities at a reasonable level to bring the remuneration of general practitioners to the same level as hospital doctors with similar qualifications within the same district or county 
would look to increase the proportion of the performance based bonus ${ }^{11} 12$ and raise the total income for primary healthcare professionals. ${ }^{13} 14$ The main reform in the primary healthcare salary system changed the source of income and its objective. Before the reform, the income was connected with the drug mark-up, which encouraged volume of prescriptions. Since the reform, income has been funded by the government, which was designed to motivate primary healthcare practitioners to focus on providing good quality services.

In addition to financial incentives, nonfinancial incentives are also important to motivate primary healthcare professionals. ${ }^{15}$ In 2011, a national guideline was issued on establishing a general practitioner (GP) system by $2020 .^{10}$ To help build this system, policies on career development of primary healthcare professionals emphasised that the GPs should have more promotion opportunities. Years of work and other requirements need to be adjusted to better evaluate GPs' qualifications for promotion. ${ }^{16}$

\section{Progress made and challenges remaining}

The financing mechanism no longer relies on drug mark-ups. Both central and local governments have invested more in primary healthcare providers, including subsidies to compensate for the loss of revenue from removal of drug mark-ups and financial arrangements to deliver basic public health services. ${ }^{17}$ For rural primary healthcare facilities, the share of direct government subsidies in revenue rose from $23 \%$ in 2010 to $37 \%$ in 2017 . For urban primary healthcare facilities, the share increased from $25 \%$ in 2010 to $45 \%$ in 2017 (fig 1). ${ }^{18}$

The number of primary healthcare professionals has steadily increased and so have their salaries. Helped by government financing and the establishment of the GP system, the total numbers of health professionals, practising doctors, and registered nurses increased by 31\%, 28\%, and $65 \%$ respectively between 2010 and $2017 .{ }^{18}$ In addition, the average annual salary for primary healthcare professionals increased about two and half times, from $¥ 22000$ (£2838; €2508; \$3190) in 2010 to $¥ 57000$ in 2017 (fig 2). In addition, social benefit programmes were expanded to include primary healthcare professionals. ${ }^{19}$

Despite the evidence of the positive effect of the policies, more work needs to be done to realign incentives for primary healthcare practitioners to improve quality of care. An unintended result of the reforms is that the use of primary healthcare as a proportion of total healthcare use has declined over the
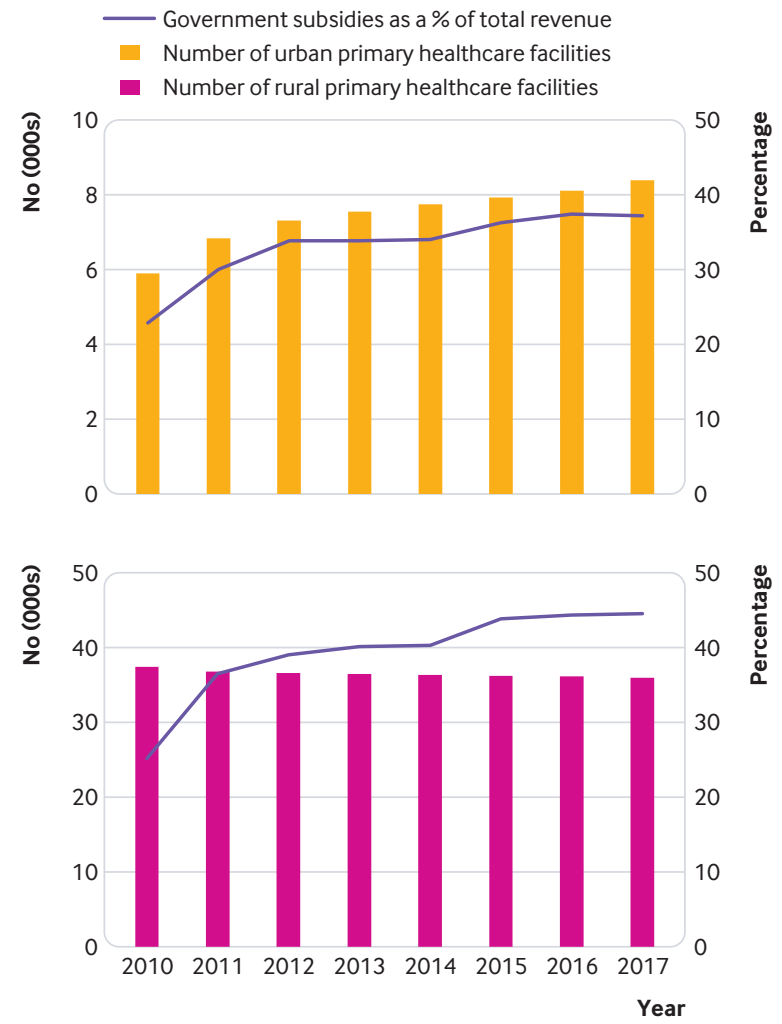

Fig 1 | Number of primary healthcare facilities and government subsidies as a percentage of total revenue, $2010-17^{18}$

past 10 years. Outpatient and inpatient visits to primary healthcare facilities as a percentage of the total number of visits to healthcare facilities-primary healthcare facilities and hospitals-decreased from $62 \%$ and $28 \%$ respectively in 2009 to $54 \%$ and $18 \%$ in 2017 (fig 3). Patients chose to bypass the primary healthcare system in favour of hospitals, which suggests that the quality of health services in primary healthcare facilities was still unsatisfactory. ${ }^{6}$

A recent study using standardised patients to assess the quality of care in primary healthcare found poor clinical

performance and that an important barrier to delivering good quality care was the gap between medical knowledge and clinical practice. ${ }^{20}$ This gap, known as the know do gap, is found in many primary healthcare systems in the developing world and may be a result of weak or misaligned incentives that fail to motivate primary healthcare professionals to deliver good quality care even when they have the correct knowledge. ${ }^{21}$ Lack of knowledge and medical incompetence are also reasons for poor care, which reflect gaps in medical education and inservice training opportunities. $^{6}$

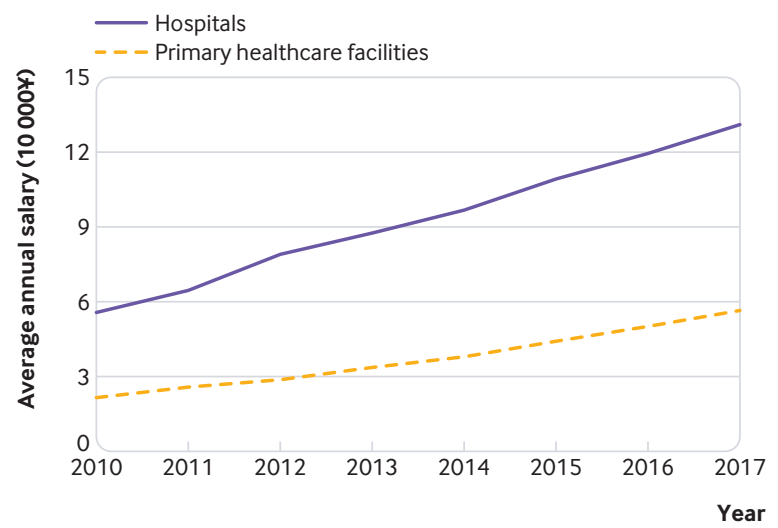

Fig 2 | Average annual salary in primary healthcare facilities and hospitals, 2010-17. ${ }^{18}$ $1 ¥=£ 0.114 ; € 0.129 ; \$ 0.145$ 


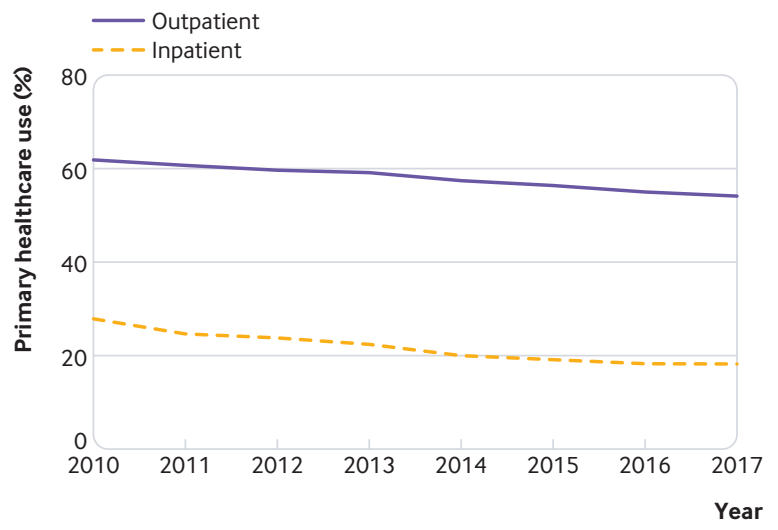

Fig 3 | Use of primary healthcare as a percentage of total use of healthcare facilities, $2010-17^{18}$

\section{What should be done to further progress?}

Moving forward, China has an historic opportunity to establish its GP system and people centred integrated care system. The country should make use of the policy momentum to strengthen its system of incentives. We highlight three policy recommendations for further progress.

Firstly, based on the experience of implementing the performance based salary system, this should be accompanied by a functioning evaluation system linked to quality. Although monitoring and evaluation based on the quality of service were built into the reform, in practice, many primary healthcare facilities linked their performance indicators to service volume rather than quality of services provided..$^{22}$ In addition, no meaningful variation existed in the bonus salary. Because primary healthcare managers were concerned about fairness, ${ }^{19}$ many facilities distributed the bonus salary equally to all healthcare professionals. This acted as a disincentive for primary healthcare doctors to individually deliver a higher quality of care. Further reform of the performance based salary system should consider adding a component in the evaluation system that is tied to both volume and performance quality indicators so that it generates variation in individual performance bonus. By doing so, the performance based salary system would motivate primary healthcare professionals more effectively.

Secondly, more policies should be considered to ensure an adequate total income for primary healthcare providers. Even if the performance based salary were implemented properly, the total income of primary healthcare providers is still low, which makes it difficult to motivate primary healthcare doctors. The salary of healthcare professionals, and particularly primary healthcare doctors, in China is not attractive compared with the average occupation (table 1). Although salaries in primary healthcare facilities have improved, the salary gap between health professionals working in primary healthcare facilities and public hospitals has widened over the past decade (fig 2). Without increasing the pay of primary healthcare professionals to an acceptable level, any effort to motivate them by adding a performance based mechanism will not improve job productivity and morale in the long term. ${ }^{24}$ In fact, a recent policy modification has considered improving the total salary. ${ }^{1416}$ In countries of the Organisation for Economic Cooperation and Development, the average salary of GPs is comparable to the average salary of physicians and surgeons and two times higher than the average salary of all occupations (Table 1). As China's economy continues to grow, setting a salary standard for GPs comparable to those internationally should be considered as a long term goal.

Thirdly, non-financial incentives, especially career development opportunities for primary healthcare professionals, should be strengthened. Although improvement of salaries may be a greater priority, non-financial incentives are weak-for example, opportunities for career development are scarce. Limited promotion prospects and an unclear career development path are common for primary healthcare providers. ${ }^{25}$ At the same time, primary healthcare facilities no longer provide a wide range of clinical services-such as minor surgery or childbirth services-and this has reduced the opportunities for primary healthcare practitioners to update and improve their clinical knowledge and practice. ${ }^{19} \mathrm{~A}$ review of the GP system in the UK showed that clinical content-especially if it is intellectually stimulating-is associated with job satisfaction. ${ }^{26}$ In addition, strategies to reform payment methods, education, and training of GPs (not discussed in detail here) are also important to reform the system of incentives.

\section{Conclusion}

Primary healthcare is the foundation of an effective health system but efforts to strengthen primary healthcare in low and middle income countries are limited. ${ }^{27}$ China's experience shows that incentive systems are important for a fully functioning primary healthcare system. Relying mainly on the market economy has generated inappropriate incentives that have led to overprescription of drugs and overuse of advanced diagnostic tests, and relying mainly on government interventions has resulted in weak incentives for primary healthcare providers. Over the past 10 years, despite achievements in removing drug mark-ups as a main source of financing for primary healthcare facilities, gaps still remain in realigning the incentives for primary healthcare providers. Further reforms should consider connecting the performance based salary system to an

\begin{tabular}{|c|c|c|c|c|}
\hline Country & Level & Measurement & Wage (\$) & Relative wage \\
\hline \multirow{4}{*}{ China } & All occupations & National average annual wage for all occupations ${ }^{18}$ & 10232 & $100 \%$ (reference) \\
\hline & Healthcare sector in general & Average annual wage for health and social services sector ${ }^{18}$ & 12166 & $118 \%$ \\
\hline & Primary healthcare & Median annual wage for community and township health centres ${ }^{6}$ & 7118 & $70 \%$ \\
\hline & Primary healthcare & Median annual wage for village clinics $^{6}$ & 3707 & $36 \%$ \\
\hline \multirow{3}{*}{ OECD } & All occupations & National average annual wage for all occupations ${ }^{23}$ & 40099 & $100 \%$ (reference) \\
\hline & Healthcare sector in general & Average annual wage for physicians and surgeons ${ }^{23}$ & 103907 & $259 \%$ \\
\hline & Primary healthcare & Average annual wage for general and family practitioners ${ }^{23}$ & 85084 & $212 \%$ \\
\hline
\end{tabular}


evaluation system linked with quality, ensuring adequate total salaries, and providing career development opportunities for primary healthcare professionals.

We thank Qingyue Meng and other colleagues at Peking University China Center for Health Development Studies for their comments on this article and Suhang Song, Siyuan Liang, Shuduo Zhou, and Ziyue Wang for help with the data and literature review. We also thank Hao Xue from Shaanxi Normal University for his comments on the article and James Chia (Liverpool School of Tropical Medicine) for editing the manuscript.

Contributors and sources: XM and XL conceived the paper. XM did the data analysis and drafted the manuscript. HW, LY and LS revised the manuscript. XM has researched health issues in developing countries, mainly in the setting of rural China. HW has over 30 years of experience in health policy globally, with a focus on health economics, financing and systems in developing countries. LY is an expert on health economics and health policy research, with a focus on public health, national medicine policy and health technology assessment. LS has a long research interest in health policy and health services, with a focus on primary care, health disparities and vulnerable populations. XL has expertise in health issues in China with a research focus on human resources. XM is the guarantor.

Competing interests: We have read and understood BMJ policy on declaration of interests and have no interests to declare.

Provenance and peer review: Commissioned; externally peer reviewed.

This article is part of a series proposed by Peking University China Center for Health Development Studies and commissioned by The BMJ. The BMJ retained full editorial control over external peer review, editing, and publication of these articles. Article handling fees (including printing, distribution, and open access fees) are funded by Peking University Health Science Center.

Xiaochen $\mathrm{Ma}$, lecturer ${ }^{1}$

Hong Wang, senior programme officer ${ }^{2}$

Li Yang, associate professor ${ }^{3}$

Leiyu Shi, professor ${ }^{4}$

Xiaoyun Liu, professor ${ }^{1}$

${ }^{1}$ China Center for Health Development Studies, Peking University, Beijing, China

${ }^{2}$ Bill and Melinda Gates Foundation, Seattle, USA

${ }^{3}$ School of Public Health, Peking University, Beijing, China

${ }^{4}$ Johns Hopkins University Bloomberg School of Public Health, Baltimore, USA
Correspondence to: $\mathrm{XMa}$

xma@hsc.pku.edu.cn

\section{(c) (1) (8) Oy Ne OPEN ACCESS}

This is an Open Access article distributed in accordance with the Creative Commons Attribution Non Commercial (CC BY-NC 4.0) license, which permits others to distribute, remix, adapt, build upon this work non-commercially, and license their derivative works on different terms, provided the original work is properly cited and the use is non-commercial. See: http://creativecommons.org/ licenses/by-nc/4.0/.

\section{Check for updates}

1 World Health Organization. The world health report 2008: primary health care now more than ever: introduction and overview. WHO, 2008.

2 Anand S, Bärnighausen T. Human resources and health outcomes: cross-country econometric study. Lancet 2004;364:1603-9. doi:10.1016/S01406736(04)17313-3

3 Yip WC, Hsiao W, Meng Q, Chen W, Sun X. Realignment of incentives for health-care providers in China. Lancet 2010;375:1120-30. doi:10.1016/ S0140-6736(10)60063-3

4 Blumenthal D, Hsiao W. Lessons from the East--China's rapidly evolving health care system. N Engl J Med 2015;372:1281-5. doi:10.1056/NEJMp1410425

5 Yip W, Hsiao W. China's health care reform: A tentative assessment. China Econ Rev 2009;20:6139. doi:10.1016/j.chieco.2009.08.003

$6 \mathrm{Li}$ X, Lu J, Hu S, et al. The primary health-care system in China. Lancet 2017;390:2584-94. doi:10.1016/ S0140-6736(17)33109-4

7 Central Committee of the Communist Party of China, Stata Council. Opinions on deepening health system reform [Chinese]. Zhongfa No 6, 2009

8 Ministry of Human Resources and Social Security. Guidelines on implementation of performance-based salary at primary health care facilities and public health institutions [Chinese]. Renshebufa No 182, 2009.

9 General Office of the State Council. Opinions on establishment and optimisation of the reimbursement scheme for primary health care facilities [Chinese]. Guobanfa No 62, 2010.

10 State Council Health System Reform Office. Guidelines on establishment of general practitioner system [Chinese]. Guofa № 23, 2011.

11 State Council. Guidelines on deepening health system reform during the 12 th five-year plan period. Guofa No 11, 2012 [Chinese].

12 General Office of the State Council. Opinions on optimisation of the essential medicines policy and operating mechanism for primary health care facilities [Chinese]. Guobanfa № 14, 2013.
13 State Council. Plan on deepening health system reform during the 13th five-year plan period [Chinese]. Guofa No 78, 2016.

14 General Office of the State Council. Opinions on optimising the training and incentive mechanism for general practitioners [Chinese]. Guobanfa No 3 , 2018.

15 Meng Q. Study on incentive factors of primary care providers [Chinese]. Chinese ] Health Policy 2012;5:4-5. doi:10.3969/j.issn.16742982.2012.03.002

16 State Council Health System Reform Office. Guidelines on advancing family doctor contract service [Chinese]. Guovigaifa No 1, 2016.

17 Meng Q, Mills A, Wang L, Han Q. What can we learn from China's health system reform?BMI 2019;365:12349. doi:10.1136/bmj. 12349

18 National Health Commission. China national health statistical yearbook [Chinese]. Peking Union Medical College Press, 2018. http://tongji.cnki.net/kns55/ Navi/YearBook.aspx?id=N2019030282\&floor=1

19 Liu X, Zhao S, Zhang M, et al. The development of rural primary health care in China's health system reform. J Asian Public Policy 2015;8:88-101. doi:10. 1080/17516234.2015.1008195

20 Sylvia S, Xue H, Zhou C, et al. Tuberculosis detection and the challenges of integrated care in rural China: A cross-sectional standardized patient study. PLOS Med 2017;14:e1002405. doi:10.1371/journal. pmed.1002405

21 Das J, Woskie L, Rajbhandari R, Abbasi K, Jha A. Rethinking assumptions about delivery of healthcare: implications for universal health coverage. BMJ 2018;361:k1716. doi:10.1136/bmj.k1716

22 Zhang L, Sun T, Zhang Y, et al. Analysis on typical cases and problems of the implementing merit pay in primary medical institutions[Chinese]. Chinese Health Economics 2016:35:70-2

23 OECD. OECD economic outlook. Vol 2018, No 1. http://dx.doi.org/10.1787/eco_outlook-v2018-1-en

24 Meng Q. Behavior and incentive mechanism of health providers[Chinese]. Chinese J Health Policy 2010;10:1-2

$25 \mathrm{Li} \mathrm{H}$, Kong P, Yu H, et al. Incentive factors influencing work behavior of primary care providers in China[Chinese]. Chinese J Health Policy 2012;3:6-11.

26 Marchand C, Peckham S. Addressing the crisis of GP recruitment and retention: a systematic review. BrJ Gen Pract 2017;67:e227-37. doi:10.3399/ bjgp17X689929

27 Kremer M, Glennerster R. Improving health in developing countries: evidence from randomized evaluations. In: Pauly MV, McGuire TG, Barros PP, eds. Handbook of health economics. Elsevier, 2011:201-315. doi:10.1016/B978-0-444-535924.00004-9

Cite this as: $B M J$ 2019;365:12406

http://dx.doi.org/10.1136/bmj.l2406 